\title{
Components of total energy expenditure in free-living elderly men (over 75 years of age): measurement, predictability and relationship to quality-of-life indices
}

\author{
BY N. J. FULLER ${ }^{1}$, M. B. SAWYER ${ }^{1}$, W. A. COWARD ${ }^{1}$, P. PAXTON ${ }^{2}$ AND M. ELIA ${ }^{1}$ \\ ${ }^{1} M R C$ Dunn Clinical Nutrition Centre, Cambridge CB2 $2 D H$ and ${ }^{2}$ Lensfield Medical Practice, \\ 48 Lensfield Road, Cambridge CB2 1EG
}

(Received 9 January 1995 - Revised 19 April 1995 - Accepted 10 May 1995)

\begin{abstract}
Current recommendations for energy requirements in the elderly are based on assumed levels of physical activity relative to BMR (1.5 $\times$ BMR). The main aim of the present study was to establish whether these recommendations might be applicable to a randomly-selected group of free-living elderly men (all over 75 years of age). BMR was measured by indirect calorimetry and total energy expenditure (TEE) by the doubly-labelled-water technique. Further aims included evaluating the applicability of a variety of BMR prediction equations and whether assessed quality of life reflected any measured indices of energy expenditure. The mean value for daily energy requirement was found to be $1.5 \times \mathrm{BMR}(89 \mathrm{~J} / \mathrm{kg}$ per min) but with substantial inter-individual variation (SD $0.2 \times B M R ; 14 \mathrm{~J} / \mathrm{kg}$ per min). The bias between measured TEE and TEE estimated (1.5 $\times$ BMR) from the various BMR predictions varied according to which equation was used $(-10-+8 \%$ of the mean) with substantial $95 \%$ limits of agreement $(28-30 \%$ of the mean). TEE and physical activity plus thermogenesis (TEE-BMR) were positively related to activities of daily living, but no relationships were apparent between these and perceived quality of life. It is concluded that, despite considerable inter-individual variability, national recommendations for energy requirements of elderly people are applicable to this randomly-selected group of free-living men over 75 years of age but that substantial variation exists when attempts are made to estimate TEE from measurements or predictions of BMR.
\end{abstract}

Physical activity levels: Basal metabolic rate: Multi-level assessment instrument

In the United Kingdom and other developed countries there is a disproportionate secular increase in the number of elderly people in the population (Office of Population Censuses and Surveys, 1991; Bureau of the Census, 1993), and this trend appears set to continue (Office of Population Censuses and Surveys, 1991). However, there is limited information concerning energy requirements of the elderly compared with other groups, despite the existing recommended levels of daily energy intake (Department of Health and Social Security, 1979; Food and Agriculture Organization/World Health Organization/United Nations University, 1985; National Research Council, 1989; Committee on Medical Aspects of Food Policy, 1991; 1992). A mean energy intake of 1.5 times BMR is currently suggested (about $88 \mathrm{~J} / \mathrm{kg}$ per min) in both the UK (Committee on Medical Aspects of Food Policy, 1992), for individuals over 60 years of age, and USA (National Research Council, 1989), for those over 51 years. In contrast, a study with doubly-labelled water (DLW) in a group of fifteen elderly males of mean age 69 (SD 1.8) years in the USA (Roberts et al. 1992) suggests that total energy expenditure (TEE) may be significantly higher (1.75 times BMR) than recommended dietary allowances. This contention is supported by a study of ten elderly, although exclusively female, subjects (aged 73 (SD 3) years) resident in the UK, in whom TEE was estimated to be a mean of 1.8 $\times$ BMR (Reilly et al. 1993). 
However, in neither of these studies had the sample groups been drawn randomly. For example, in the study by Roberts et al. (1992) recruitment was based on proximity to the research centre, and Reilly et al. (1993) reported that their study comprised healthy, selfselected and highly-motivated individuals not representative of the older community.

The purpose of the present study was to measure TEE by DLW and BMR by indirect calorimetry in a group of elderly men, randomly selected from a general practice (GP) register, in order to establish (a) whether or not current national recommendations are appropriate, (b) reference data for comparison with other groups, (c) the ability of certain empirical equations to predict both BMR and TEE (1.5 $\times$ BMR) for this age-group and (d) the extent of any potential associations between levels of energy expenditure and indices of quality of life as assessed by multi-level assessment instrument (MAI; Lawton et al. 1982).

\section{METHODS}

\section{Subjects}

Subjects were selected at random from a GP register provided that the following criteria were fulfilled (forty-four records were appropriate): (a) males of over 75 years of age; (b) free-living in the community (Cambridge residents); (c) sufficient mental and physical capacity (with help if needed) to comply with study requirements (specifically, ability to swallow quantitatively the doubly-labelled water dose and to provide accurately-timed urine samples, two subjects were excluded on this basis); (e) although the presence of overt disease per se did not preclude involvement, if it was felt that participation might cause undue distress (e.g. if death was imminent from terminal illness) then these individuals were not approached (two subjects were excluded).

Of the forty subjects approached by letter of introduction with simple explanation, seven were uncontactable and ten refused to take part, so that $70 \%$ participated in the study. There was no indication that the individuals who did not participate were in any way aberrant in terms of activity levels. This tentative conclusion was based on a semiquantitative subjective assessment previously obtained on all patients over 75 years by a practice nurse as part of a GP survey. There was fairly good agreement between this assessment and indices of activity obtained from both energy expenditure measurements and questionnaire for the subjects who did participate.

The characteristics of the twenty-three white Caucasian subjects studied were: median age 82 (range 76-88) years (mean 82 (SD 3) years), mean weight 72.4 (SD 10.5) kg, height 1.71 (SD 0.08) m, BMI 24.8 (SD 3.0) $\mathrm{kg} / \mathrm{m}^{2}$, fat-free mass (FFM; estimated from ${ }^{2} \mathrm{H}$ dilution space, see p. 164) $50 \cdot 2$ (SD 6.2) kg, body fat (as percentage body weight (W), estimated from ${ }^{2} \mathrm{H}$ dilution space) $30 \cdot 4$ (SD 4.6) \%. Of the six subjects who lived in sheltered accommodation, three were married and three were single (all widowed); and of the seventeen living in their own homes, ten were married and seven were single (also all widowed).

\section{Weight and height}

W for each subject was measured using a portable Tefal 74150 digital weighing scale, previously validated against a Sauter Type E1210 electronic scale (Todd Scales, Studlands Park Industrial Estate, Newmarket, Suffolk). Standing height was measured against a wallmounted stadiometer.

\section{Measurement of energy expenditure}

Total energy expenditure. Before the study an early-morning urine sample was taken for measurement of baseline values of ${ }^{2} \mathrm{H}$ - and ${ }^{18} \mathrm{O}$-labelled water. Sterile filtered DLW was administered orally; $\mathrm{H}_{2}{ }^{18} \mathrm{O}$ (EG \& G Mound Applied Technologies, Miamisburg, OH, 
USA) at $0 \cdot 174 \mathrm{~g} / \mathrm{kg} \mathrm{W}$ and ${ }^{2} \mathrm{H}_{2} \mathrm{O}\left(99 \cdot 8 \%\right.$ atoms percent excess ${ }^{2} \mathrm{H}_{2} \mathrm{O}$; Sigma Chemical Co. Ltd, Poole, Dorset) at $0.070 \mathrm{~g} / \mathrm{kg} \mathrm{W}$. The subjects followed their usual daily routines and collected a timed spot urine sample from the second (or subsequent) bladder voiding of the day for $21 \mathrm{~d}$. Samples were gathered in daily and frozen at $-20^{\circ}$ until analysed using an Aqua Sira (VG Isogas, Middlewich, Ches.) isotope-ratio mass spectrometer. The accuracy of repeated measurements of known standards and the precision of duplicate samples, relative to standard mean ocean water, has been reported previously (Pullicino et al. 1993).

$\mathrm{CO}_{2}$ production rate was calculated using a multi-point method from the following equation (Coward, 1988):

$$
F_{\mathrm{CO}_{2}}=\left(k_{o} \cdot V_{o}-k_{d} \cdot V_{d}-S\left[f_{2}-f_{1}\right]\right) /\left(2 f_{3}+Q\left[f_{2}-f_{1}\right]\right),
$$

where, $F_{\mathrm{CO}_{2}}$ is $\mathrm{CO}_{2}$ production rate $(1 / \mathrm{d}) ; k_{o}$ and $k_{d}$ are the slopes of the log plots of isotope enrichments $v$. time (d) for $\mathrm{O}(o)$ and ${ }^{2} \mathrm{H}(d)$ respectively, $V_{o}$ and $V_{d}$ are intercepts (1/antilog) of these $\log$ plots, $Q$ is the number of mol water expired per $\mathrm{mol} \mathrm{CO}_{2}$ (assumed to be $1 \cdot 1$ ), $S$ is transcutaneous loss of water (assumed to be $27.3 \mathrm{~mol} / \mathrm{d}$ ), $f_{1}, f_{2}$ and $f_{3}$ are the proportions ${ }^{2} \mathrm{H}$ in water $(0.941),{ }^{18} \mathrm{O}$ in water $(0.992)$ and ${ }^{18} \mathrm{O}$ in $\mathrm{CO}_{2}(1.037)$ respectively. The validity of these assumptions has been discussed previously (Coward, 1988). However, because no data exist for fractionation due to insensible water loss in the elderly, estimates of potential errors were calculated for all individuals in the present study by assuming that actual transcutaneous loss of water was either implausibly low $(0.0 \mathrm{~mol} / \mathrm{d})$ or high $(54.6 \mathrm{~mol} / \mathrm{d})$. Substituting these values into the TEE calculation resulted in mean relative errors of only 3.8 (range $2 \cdot 7-5 \cdot 4$ ) \% above or below respectively the values obtained when applying an assumed loss of $27.3 \mathrm{~mol} / \mathrm{d}$.

TEE was calculated assuming that the energy equivalent of $\mathrm{CO}_{2}$ was $23.8 \mathrm{~kJ} / 1$ which applies to subjects who are close to nutrient balance whilst ingesting a 'Western'-type diet (assumed RQ of about 0.85; Elia, 1991).

Basal metabolic rate. $\mathrm{O}_{2}$ consumption and $\mathrm{CO}_{2}$ production rates were measured, after an overnight fast and with the subjects supine and completely at rest in a thermoneutral environment (room temperature, 22-26 ), using a Deltatrac MBM-100 mobile indirect calorimeter calibrated according to the manufacturer's instructions. Validation and mean differences between duplicate measurements have been reported elsewhere (Reilly et al. 1993). BMR was calculated from these rates using the equation of Elia \& Livesey (1992):

$$
\text { energy expenditure }(\mathrm{kJ})=15.818 \times \mathrm{O}_{2}(\mathrm{l})+5 \cdot 176 \times \mathrm{CO}_{2}(\mathrm{l}) \text {. }
$$

Physical activity plus thermogenesis level $(P A L)$ ratio and $P A L$ increment. The PAL ratio and increment were calculated from TEE and BMR:

$$
\begin{aligned}
\text { PAL ratio } & =\text { TEE }: \text { BMR, } \\
\text { PAL increment } & =\text { TEE }- \text { BMR }(\mathrm{kJ}) .
\end{aligned}
$$

Normalized energy expenditures. TEE, BMR and PAL increment per $\mathrm{kg} \mathrm{W}$ and per $\mathrm{kg}$ FFM (see p. 164) were calculated from the whole-body measurements.

\section{Prediction of energy expenditure}

BMR was predicted from the following equations, incorporating terms involving $\mathrm{W}(\mathrm{kg})$, height $(\mathrm{m})$ and age (years):

$$
\text { BMR }(\mathrm{MJ} / 24 \mathrm{~h})=0.0575 \mathrm{~W}+2.0934 \text { height }-0.0283 \text { age }+0.2781 \text {, }
$$

for men of all ages (Harris \& Benedict, 1919);

$$
\text { BMR }(M J / 24 h)=0.0372 \mathrm{~W}+1.2447 \text { height }+0.4674 \mathrm{~S}+1.2293,
$$


for men of all ages (Quenouille et al. 1951), where $\mathrm{S}$ is surface area $\left(\mathrm{m}^{2}\right)$ which was estimated from W and height using the equation of Dubois \& Dubois (1916), assumed humidity was $75 \%$ and an adjustment for age was included (Table A 7 of Elia, 1992);

$$
\begin{aligned}
& \text { BMR }(M J / 24 \mathrm{~h})=0.049 \mathrm{~W}+2.459, \\
& \text { BMR }(M J / 24 \mathrm{~h})=0.038 \mathrm{~W}+4.068 \text { height }-3.491,
\end{aligned}
$$

for men aged 60 years and above (Schofield, 1985);

$$
\text { BMR }(\mathrm{MJ} / 24 \mathrm{~h})=0.0427 \mathrm{~W}+3 \cdot 678 \text {, }
$$

for men of all ages (Owen et al. 1987);

$$
\begin{array}{lr}
\operatorname{BMR}(\mathrm{MJ} / 24 \mathrm{~h})=0.0515 \mathrm{~W}+2.946, & (5 a) \\
\operatorname{BMR}(\mathrm{MJ} / 24 \mathrm{~h})=0.0418 \mathrm{~W}+2.615 \text { height }-0.0209 \text { age }+0.0209,(5 b)
\end{array}
$$

for men of all ages (Mifflin et al. 1990);

$$
\operatorname{BMR}(\mathrm{MJ} / 24 \mathrm{~h})=0.0448 \mathrm{~W}-0.0377 \text { age }+6.017 \text {, }
$$

for men aged 51-82 years (Fredrix et al. 1990);

$$
\operatorname{BMR}(\mathrm{MJ} / 24 \mathrm{~h})=0.035 \mathrm{~W}+3.434 \text {, }
$$

for men aged 75 years and above (Committee on Medical Aspects of Food Policy, 1991).

For detailed presentation and discussion of BMR prediction equations, see Elia (1992).

TEE was estimated from these equations assuming a PAL ratio of $1.5 \times \mathrm{BMR}$.

\section{Estimation of body composition}

Total body water (TBW) was estimated from ${ }^{2} \mathrm{H}\left(N_{d}\right)$ and ${ }^{18} \mathrm{O}\left(N_{o}\right)$ dilution spaces, obtained from 1/antilog of the intercepts $\left(V_{o}\right.$ and $\left.V_{d}\right)$ of log plots of the isotope disappearance rates (see p. 163), assuming that ${ }^{2} \mathrm{H}$ and ${ }^{18} \mathrm{O}$ dilution spaces were $1.04 \mathrm{TBW}$ and 1.01 TBW respectively:

$$
\begin{aligned}
\operatorname{TBW}(\mathrm{mol}) & =\left(\left(N_{d} / 1 \cdot 04\right)+\left(N_{o} / 1 \cdot 01\right)\right) / 2, \\
\operatorname{TBW}(\mathrm{kg}) & =\operatorname{TBW}(\mathrm{mol}) / 18020 .
\end{aligned}
$$

FFM was estimated by assuming that the hydration proportion of FFM was 0.72 (Siri, 1961), and body fat mass (kg) was estimated as difference between W and FFM.

\section{Quality-of-life questionnaire}

MAI (MAI Manual; Dr M. Powell Lawton, Philadelphia Geriatric Center, 5301 Old York Road, Philadelphia, PA 19141, USA) was the questionnaire used to assess quality of life in the subjects studied. Devised by Lawton et al. (1982), the MAI was designed as a research and services assessment tool for use with elderly people in the community. It was based on the concept that quality of life should be assessed in four dimensions: behavioural competence, psychological well-being, perceived quality of life and environmental quality. Functional abilities were based on a hierarchy of increasingly complex activities, from simple biological functioning to social interaction. Although incorporating a variable number of items and scale size, assessment in seven domains (health problems, cognition, activities of daily living, psychological well-being, environmental quality, meaningful timeuse and social interaction) and the summed quality-of-life index enabled comparisons with independent attributes and between groups. Reliability and validity were reported to be good (Lawton et al. 1982) and, although some aspects of the scale (e.g. social and environmental domains) were considered to require further sophistication (Lawton et al. 1982), others that are of particular relevance to the present study (e.g. the activities of daily 
living (ADL) and physical health) appeared to be more robust (for general comparative description of this and other similar instruments, see McDowell \& Newell, 1987).

Wherever it was felt that the MAI indices as formulated could be improved on with respect to gaining a more representative measure of physical activity, this was implemented. Specifically, the activities of daily living (ADL) index includes an assessment of instrumental ADL (IADL) which are the daily activities that the subject is capable of doing (laundry, cleaning etc). This index makes no provision for IADL that are actually undertaken on a regular basis (e.g. the index establishes whether the subject could clean the house should the need arise, not if he actually does clean it regularly). Therefore, an index to include those IADL which were actually undertaken on a regular basis (IADL-does) as opposed to those that could be undertaken (IADL-can) was compared with measured indices of energy expenditure, including incremental physical activity levels.

\section{Statistics}

Wherever appropriate, results are expressed as mean, SD, median and range. Comparisons between groups were made using Student's $t$ test. Possible associations were assessed by Pearson's correlation coefficient $(r)$.

The extent of agreement between two alternative methods was assessed by calculating bias (mean of differences between methods) and 95\% limits of agreement (2SD of these differences) between measurements obtained from each method (Bland \& Altman, 1986). Where appropriate, any relationship between bias and measurement magnitude (mean of estimates from the two methods) was examined, usually using the correlation coefficient. If such a relationship was shown to be non-significant, the bias (if large enough to be materially important) could be eliminated by subtraction to allow results from alternative methods to be used interchangeably, provided that the limits of agreement were acceptably small.

\section{Ethical approval}

This study was approved by the local Ethical Committee of the Dunn Clinical Nutrition Centre, and informed consent was obtained from each subject.

\section{RESULTS}

The weights of all subjects (see p. 162) were virtually identical at the beginning and end of the study (the slight oedema evident in three subjects persisted throughout). Only one subject smoked cigarettes and one a pipe. Many of the twenty-three subjects showed some evidence of age-related morbidity: fifteen subjects had either an anterio-posterior or a lateral curvature of the spine (by sight to an untrained observer); twenty-one subjects wore glasses for at least some of the time, and seven subjects had glaucoma or cataract; nine subjects used hearing aids; two subjects had hip replacements; two subjects had diabetes; sixteen subjects claimed episodes of stroke, high blood pressure, angina etc, and four subjects were physically impaired requiring walking aids (three used walking sticks and one a frame).

The mean ratio of the dilution spaces $\left({ }^{2} \mathrm{H}:{ }^{18} \mathrm{O}\right)$ of these subjects was found to be 1.033 (SD 0.019) and no correction was made to normalize individual ratios for the determination of energy expenditure (Coward, 1988). Descriptive statistics (means and SD, median and range etc.) for TEE, BMR and PAL for the whole-body, per $\mathrm{kg} \mathrm{W}$ and per kg FFM are shown in Table 1. No significant difference was observed for any aspect of measured energy expenditure between the groups of married and single subjects (irrespective of whether or not they were living in their own homes or in sheltered accommodation) or between married and single subjects living in their own home. No attempt was made to compare 
Table 1. Total energy expenditure, BMR and the energy cost of physical activity and thermogenesis for elderly men*

(Mean values and standard deviations, medians and ranges for twenty-three subjects)

\begin{tabular}{|c|c|c|c|c|}
\hline & Mean & SD & Median & Range \\
\hline \multicolumn{5}{|l|}{ Total energy expenditure } \\
\hline Whole body $(\mathrm{MJ} / \mathrm{d})$ & $9 \cdot 2$ & $1 \cdot 4$ & $9 \cdot 3$ & $6 \cdot 3-12 \cdot 5$ \\
\hline Per $\mathrm{kg}$ body wt $(\mathrm{J} / \mathrm{kg}$ per $\mathrm{min})$ & $89 \cdot 4$ & $14 \cdot 2$ & $89 \cdot 2$ & $65 \cdot 1-114 \cdot 2$ \\
\hline Per kg FFM (J/kg per min) & $130 \cdot 3$ & $17 \cdot 3$ & $131 \cdot 6$ & $105 \cdot 8-169 \cdot 6$ \\
\hline \multicolumn{5}{|l|}{ BMR } \\
\hline Whole body $(\mathrm{MJ} / \mathrm{d})$ & 60 & 0.5 & $6 \cdot 0$ & $4 \cdot 3-7 \cdot 0$ \\
\hline Per kg body wt ( $\mathrm{J} / \mathrm{kg}$ per $\min )$ & $58 \cdot 2$ & $6 \cdot 3$ & $57 \cdot 2$ & $47 \cdot 5-71 \cdot 0$ \\
\hline Per kg FFM (J/kg per min) & $85 \cdot 0$ & $7 \cdot 1$ & $84 \cdot 4$ & $74 \cdot 2-95 \cdot 6$ \\
\hline \multicolumn{5}{|l|}{ Physical activity plus thermogenesis } \\
\hline Whole body $(\mathrm{MJ} / \mathrm{d})$ & $3 \cdot 2$ & $1 \cdot 2$ & $3 \cdot 1$ & $0 \cdot 9-6 \cdot 1$ \\
\hline Per kg body wt (J/kg per min) & $31 \cdot 2$ & $12 \cdot 2$ & $29 \cdot 3$ & $9 \cdot 4-56 \cdot 0$ \\
\hline Per kg FFM (J/kg per min) & $45 \cdot 3$ & 17.0 & $44 \cdot 5$ & $15 \cdot 9-83 \cdot 1$ \\
\hline Physical activity level ratiot & 1.5 & 0.2 & 1.5 & $1 \cdot 2-2 \cdot 0$ \\
\hline
\end{tabular}

FFM, fat-free mass.

* For details of subjects and procedures, see pp. 162-164.

$\uparrow$ Total energy expenditure:BMR.

Table 2. Total energy expenditure, BMR and the energy cast of physical activity and thermogenesis for groups of elderly men living in their own homes and in sheltered accommodation*

(Mean values and standard deviations for seventeen subjects living in their own homes and for six subjects in sheltered accommodation)

\begin{tabular}{|c|c|c|c|c|c|}
\hline & \multicolumn{2}{|c|}{ Own home } & \multicolumn{2}{|c|}{$\begin{array}{c}\text { Sheltered } \\
\text { accommodation }\end{array}$} & \multirow{2}{*}{$\begin{array}{c}\text { Statistical } \\
\text { significance o } \\
\text { difference: } P\end{array}$} \\
\hline & Mean & SD & Mean & SD & \\
\hline \multicolumn{6}{|l|}{ Total energy expenditure } \\
\hline Whole body (MJ/d) & $9 \cdot 6$ & $1 \cdot 3$ & $8 \cdot 2$ & 1.4 & 0.05 \\
\hline Per $\mathrm{kg}$ body wt $(\mathrm{J} / \mathrm{kg}$ per min) & $93 \cdot 0$ & 13.6 & 79.1 & $11 \cdot 2$ & 0.05 \\
\hline Per kg FFM (J/kg per min) & $134 \cdot 3$ & $17 \cdot 3$ & 118.9 & $12 \cdot 3$ & 0.05 \\
\hline \multicolumn{6}{|l|}{ BMR } \\
\hline Whole body $(\mathrm{MJ} / \mathrm{d})$ & $6 \cdot 0$ & 0.6 & 6.0 & 0.4 & NS \\
\hline Per kg body wt (J/kg per min) & $58 \cdot 3$ & $6 \cdot 5$ & 57.7 & $6 \cdot 3$ & NS \\
\hline Per kg FFM (J/kg per min) & $84 \cdot 3$ & $7 \cdot 1$ & 87.0 & 7.5 & NS \\
\hline \multicolumn{6}{|l|}{ Physical activity plus thermogenesis } \\
\hline Whole body $(\mathrm{MJ} / \mathrm{d})$ & 3.6 & $1 \cdot 1$ & $2 \cdot 3$ & $1 \cdot 2$ & 0.05 \\
\hline Per kg body wt (J/kg per min) & $34 \cdot 7$ & $11 \cdot 2$ & $21 \cdot 4$ & 9.9 & 0.05 \\
\hline Per kg FFM (J/kg per min) & $50 \cdot 0$ & $15 \cdot 5$ & 31.9 & $14 \cdot 2$ & 0.05 \\
\hline Physical activity level ratio $\nmid$ & 1.6 & $0 \cdot 2$ & $1 \cdot 4$ & 0.2 & 0.05 \\
\hline
\end{tabular}

FFM, fat-free mass.

* For details of subjects and procedures, see pp. 162-164.

$\dagger$ Total energy expenditure:BMR. 

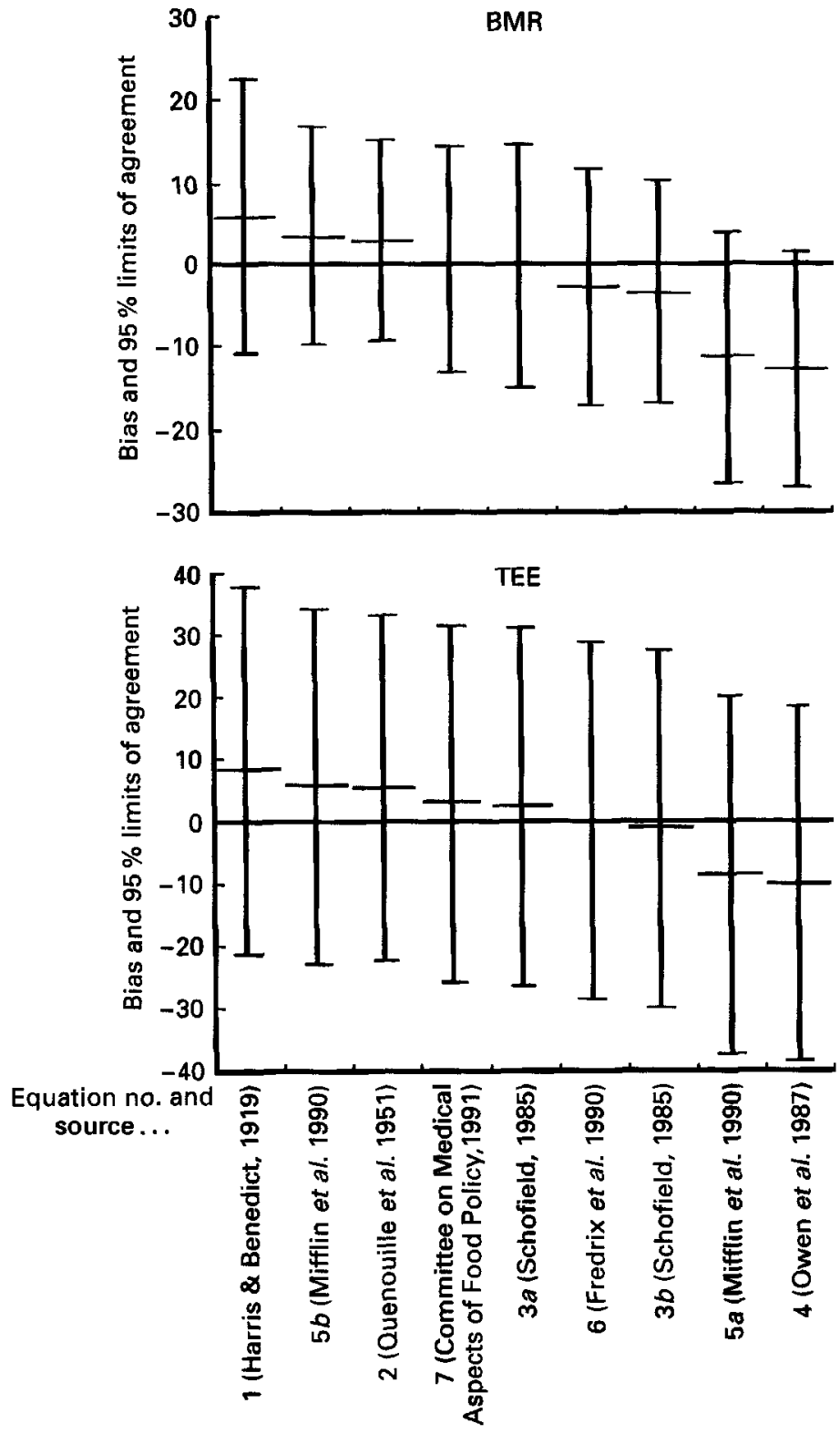

Fig. 1. Extent of agreement (represented as percentage of the mean value: $5999 \mathrm{~kJ} / 24 \mathrm{~h}$ for BMR and $9224 \mathrm{~kJ} / 24 \mathrm{~h}$ for TEE) between measured and predicted estimates of BMR and total energy expenditure (TEE). The bias was related to the magnitude of BMR for the Harris \& Benedict (1919) equation (negative relationship) and for the Committee on Medical Aspects of Food Policy (1991) equation (positive); it was positively related to the magnitude of TEE for all equations except the Harris \& Benedict (1919) prediction (no relationship). For details of subjects and procedures, see pp. 162-164 and for equations, see pp. 163-164.

married and single subjects residing in warden-controlled sheltered accommodation because of low numbers (only three in each group). Although no differences were observed between groups in terms of age, W, height and FFM, significant differences were found in TEE (whole body, per kg W and per kg FFM), PAL increment (whole body, per kg W and 
Table 3. Indices of perceived quality of life (assessed by multi-level assessment instrument; Lawton et al. 1982) for men over 75 years old and free-living in the community*

(Mean values, standard deviations and ranges)

\begin{tabular}{|c|c|c|c|c|}
\hline & Mean & SD & Range & Possible range $\dagger$ \\
\hline \multicolumn{5}{|l|}{ Physical-health domain } \\
\hline Sum & $66 \cdot 0$ & $3 \cdot 9$ & $55-71$ & $33-74$ \\
\hline Self-rated health & $10 \cdot 4$ & $2 \cdot 0$ & $5-13$ & $4-13$ \\
\hline Health behaviour & $8 \cdot 1$ & 1.0 & $6-9$ & $3-9$ \\
\hline Health conditions & $47 \cdot 4$ & 1.7 & $43-50$ & $25-50$ \\
\hline \multicolumn{5}{|l|}{ Cognitive domain } \\
\hline Sum & $14 \cdot 1$ & $1 \cdot 2$ & $10-15$ & $0-15$ \\
\hline Intellectual functioning & 10.8 & 0.4 & $10-11$ & $0-11$ \\
\hline Cognitive symptoms & $3 \cdot 3$ & $1 \cdot 0$ & 04 & 04 \\
\hline \multicolumn{5}{|c|}{ Activities of daily living (ADL) domain } \\
\hline Sum & 47.4 & $2 \cdot 9$ & $45-48$ & $16-48$ \\
\hline Personal self-maintenance & $20 \cdot 9$ & $0 \cdot 2$ & $20-21$ & $7-21$ \\
\hline Instrumental ADL & $26 \cdot 5$ & 0.9 & $24-27$ & $9-27$ \\
\hline \multicolumn{5}{|l|}{ Personal-adjustment domain } \\
\hline Sum & $10 \cdot 6$ & $2 \cdot 5$ & $4-14$ & $0-14$ \\
\hline Morale & $6 \cdot 1$ & 1.9 & $2-9$ & $0-9$ \\
\hline Psychological symptoms & $4 \cdot 4$ & 0.8 & $2-5$ & $0-5$ \\
\hline \multicolumn{5}{|l|}{ Social-interactions domain } \\
\hline Sum & $42 \cdot 9$ & $17 \cdot 9$ & $28-89$ & $14-117$ \\
\hline Friends interaction & $28 \cdot 5$ & $15 \cdot 9$ & $5-37$ & $5-37$ \\
\hline Family interaction & $14 \cdot 4$ & $6 \cdot 1$ & 426 & $3-24$ \\
\hline Time-use domain & $46 \cdot 3$ & 15.9 & $24-78$ & $19-140$ \\
\hline \multicolumn{5}{|l|}{ Environmental domain } \\
\hline Sum & $61 \cdot 8$ & $4 \cdot 6$ & $53-67$ & $24-68$ \\
\hline Subjective housing & $25 \cdot 0$ & $2 \cdot 1$ & $20-27$ & $9-27$ \\
\hline Subjective neighbourhood & $31 \cdot 0$ & $3 \cdot 2$ & $25-35$ & $12-35$ \\
\hline Personal security & $5 \cdot 7$ & 0.5 & $5-6$ & $3-6$ \\
\hline \multicolumn{5}{|l|}{ Quality of life } \\
\hline Sum + & $316 \cdot 7$ & $29 \cdot 8$ & $258-357$ & $106-476$ \\
\hline
\end{tabular}

* For details of subjects and procedures, see p. 162 and pp. 164-165 respectively.

$\uparrow$ For each index, maximum and minimum values possible are given.

+ The sub-indices for physical-health and social domains contain additional items that are not shown but which contribute to quality of life.

per kg FFM), and PAL ratio ( $P<0.05$, in all cases) between subjects living in their own homes and those in sheltered accommodation (Table 2); this was also despite the lack of significant differences between groups for BMR (Table 2).

The bias and $95 \%$ limits of agreement between BMR measured by the Deltatrac MBM100 and that estimated using BMR prediction equations (measured minus predicted) are presented in Fig. 1, in terms of percentage relative to the mean of the measured values (5999 (SD 545) kJ/24 h). Similarly, bias and $95 \%$ limits of agreement between TEE measured by the DLW method (mean 9224 (SD 1449) kJ/24 h) and that calculated from the BMR prediction equations, multiplied by a factor of 1.5 to account for physical activity, are also given in Fig. 1. Also shown are significant ( $5 \%$ probability) linear relationships between magnitude of measurement and difference between methods.

Table 3 summarizes the results of the MAI and includes all sub-indices, domain indices and a summed index of quality of life. There were no significant differences in the overall 
Table 4. Relationships* between measured energy expenditure and appropriate quality-oflife domains $\dagger$ for men over 75 years old and free living in the community $\ddagger$

\begin{tabular}{|c|c|c|c|c|}
\hline & \multicolumn{4}{|c|}{ Multi-level assessment instrument $\S$ domain } \\
\hline & $\begin{array}{l}\text { Activities of } \\
\text { daily living } \\
\text { (ADL; actually } \\
\text { performed) }\end{array}$ & Mobility & $\begin{array}{l}\text { Mobility } \\
\text { plus ADL }\end{array}$ & $\begin{array}{l}\text { Quality of life } \\
\text { (sum of all } \\
\text { domains) }\end{array}$ \\
\hline \multicolumn{5}{|l|}{ Total energy expenditure } \\
\hline Whole body & +0.44 & +0.46 & +0.53 & - \\
\hline Per kg body wt & +0.59 & - & +0.47 & - \\
\hline Per kg fat-free mass & +0.49 & - & +0.41 & - \\
\hline \multicolumn{5}{|l|}{ BMR } \\
\hline Whole body & - & +0.42 & - & - \\
\hline Per kg body wt & - & - & - & - \\
\hline Per $\mathrm{kg}$ fat-free mass & - & 一 & - & - \\
\hline \multicolumn{5}{|c|}{ Physical activity level increment } \\
\hline Whole body & +0.47 & - & +0.47 & - \\
\hline Per kg body wt & +0.55 & - & +0.46 & - \\
\hline Per kg fat-free mass & +0.52 & - & +0.44 & - \\
\hline \multicolumn{5}{|c|}{ Physical activity level ratio\| } \\
\hline & +0.48 & - & +0.47 & - \\
\hline
\end{tabular}

* Correlation coefficient $(r)$ given only if there is a significant $(P<0.05)$ straight-line relationship between these indices.

$\dagger$ No other domain within the quality-of-life assessment was related to energy expenditure in any way.

$\$$ For details of subjects and procedures, see p. 162 and pp. 162-165 respectively.

$\S$ For details, see Lawton et al. (1982).

\| Total energy expenditure: BMR.

quality-of-life index between subjects living in their own home and those in sheltered accommodation, between married and single subjects, or between married and single subjects living in their own homes. The only significant differences in individual domains were found to be for IADL-does (regularly performed activities) and mobility between subjects living in their own home and in sheltered accommodation, and those married $v$. those single subjects living in their own homes.

Relationships that exist between energy expenditure and MAI indices are shown in Table 4. Significant relationships are evident for indices including IADL-does (regularly performed activities). IADL-can (activities that can be undertaken, but not necessarily on a regular basis) demonstrated no significant relationship with energy expenditure. Neither the summed quality-of-life index nor other MAI indices showed significant relationship with any index of energy expenditure, with the exception of mobility where a positive relationship was shown to exist for both whole-body TEE and BMR ( $r 0.46$ and 0.42 respectively). Body fat (relative to $W$ ) was found to be significantly and inversely related to TEE and BMR on a whole-body basis and to IADL $(r-0.58,-0.63$ and -0.43 respectively). The waist: hip ratio (not shown) also reflected this finding $(r-0.45,-0.39$ and -0.51 respectively).

\section{DISCUSSION}

Certain features distinguish the present report on energy expenditure in elderly men from similar studies in which the DLW technique was used. The present study is characterized by its larger sample size, older age-group and, most importantly, the random nature of 
selection. The mean age of the men $(n 23)$ in the present study was 82 (SD 3 ) years compared with means of 68-72 (with SD of 1.8-6.0) years reported by Roberts et al. (1992), Goran \& Poehlman (1992) and Pannemans \& Westerterp (1994). As no randomized procedure was used in other studies there is a likelihood that selection may have been biased towards selfselected highly-motivated individuals (Reilly et al. 1993) not wholly representative of the older population. The large inter-individual variation shown in TEE and PAL increment (Table 1) confirms this previous finding in elderly people (Goran \& Poehlman, 1992; Roberts et al. 1992; Reilly et al. 1993; Pannemans \& Westerterp, 1994) and supports the use of appropriate factors for recommending energy intake at different levels of physical activity (e.g. Committee on Medical Aspects of Food Policy, 1992). However, despite this variation the mean results for the group as a whole support the continued use of existing national recommendations in both the UK (Committee on Medical Aspects of Food Policy, 1992) and USA (National Research Council, 1989) for estimating energy requirements $(1.5 \times \mathrm{BMR})$ in elderly men of over 75 years of age. Notwithstanding lack of validation of the DLW method at various levels of physical activity, especially in the elderly, these recommendations can now be based on measured, rather than predicted, values (e.g. Young, 1992).

However, it is apparent that these recommendations cannot be applied universally. For example, the energy requirements of PAL increment and TEE are apparently greater for subjects (married or single) living in their own homes than for those in sheltered accommodation (Table 2), despite showing similar mean BMR. It is not known whether the lower energy requirements of residents in sheltered accommodation are largely due to underlying disability or disease, creating the initial need for a warden-controlled environment, or whether they result from living under such conditions. Although this is an important consideration that needs to be addressed longitudinally, no appropriate data were obtained in the present cross-sectional study regarding the reasons behind the need for sheltered accommodation. There were no detectable differences in indices of energy expenditure between the groups of married and single subjects living in their own homes, suggesting that levels of physical activity are the same regardless of marital status (although this may not be true in terms of physical activity patterns, see p. 171).

Attention is drawn to errors that may be associated with the indiscriminate use of some reference equations to predict BMR and TEE in subjects of such advanced age (Fig. 1). For example, inappropriate application of the equation suggested by Owen et al. (1987), which systematically overestimated BMR by $772 \mathrm{~kJ} / 24 \mathrm{~h}(12.9 \%)$, would lead to excessive estimates of energy requirements for this particular age-group. In general, the results have shown that BMR prediction equations derived from samples comprising higher proportions of elderly subjects (e.g. Schofield, 1985; Fredrix et al. 1990; Committee on Medical Aspects of Food Policy, 1991) performed better than those of predominantly younger subjects (e.g. Owen et al. 1987; Mifflin et al. 1990), reaffirming that predictions should only be applied in appropriate circumstances (i.e. in populations from which the equation was derived, or on which it had been validated, and within the specified age-range). This point is illustrated further by improvement in the prediction capability of the Harris \& Benedict (1919) equation (established on a sample of 136 men aged 16-63 years) by Roza \& Shizgal (1984), who derived an alternative equation from an extension ( $168 \mathrm{men})$ of this same database by data from a greater number of older individuals (Benedict, 1935), including five men of

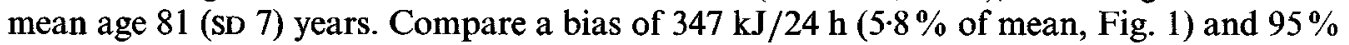
limits of agreement of $1010 \mathrm{~kJ} / 24 \mathrm{~h}(16.8 \%$, Fig. 1) with 94 and $981 \mathrm{~kJ} / 24 \mathrm{~h}$ respectively, obtained using the equation of Roza \& Shizgal (1984). This point is substantiated by use of the equation derived by Kleiber (1975) from further analysis of the Harris \& Benedict (1919) data but without additional data from older men. Despite improvement in the $95 \%$ 
limits of agreement $(836 \mathrm{~kJ} / 24 \mathrm{~h})$ there was no material change observed in bias $(333 \mathrm{~kJ} / 24 \mathrm{~h})$ between this equation and measured BMR. Aside from this, results concerning the Food and Agriculture Organization/World Health Organization/United Nations University (1985) BMR prediction equation are not shown because the extent of agreement with measured BMR was similar to that with the Schofield (1985) equation (being an extension of the same database). In addition, the application of prediction equations to groups of ethnic origins (for further discussion, see Elia, 1992) or of body composition characteristics different from those on which the equation was derived may also be a source of error. For example, the Mifflin et al. (1990) and especially the Owen et al. (1987) equations comprise substantial proportions of obese individuals. The relatively poor agreement between measured BMR and the Brody (1945) equation (data not shown) probably arose because this equation was established to predict energy expenditure in different species rather than for specific use in older men. These same BMR equations proved to be less reliable when attempts were made to predict TEE (1.5 $\times$ BMR). The large range of values for bias between measured TEE and predicted TEE (Fig. 1) probably reflect the large inter-individual variations in physical activity for this group of subjects (see $\mathrm{p}$. 170).

The quality of life of this randomly-selected sample of men was apparently better than that of the 253 community residents (mean age 76 years, $57 \%$ female) used for validation of the MAI (Lawton et al. 1982; and MAI Manual (see pp. 164-165). Indices in all domains were significantly lower in the Lawton et al. (1982) study (apart from social interactions) compared with the present study: for physical health 63.7 (SD 4.8) v. 66.0 (SD 3.9), cognitive 13.3 (SD 2.6) v. 14.1 (SD 1.2), ADL-can 45.1 (SD 4.6) v. 47.4 (SD 2.9), personal adjustment 9.9 (SD 3.5) v. 10.6 (SD 2.5), social interactions 56.8 (SD 15.8) v. 42.9 (SD 17.9), time-use 38.1 (SD 11.8) v. 46.3 (SD 15.9), environment 58.8 (SD 6.4) v. 61.8 (SD 15.9), and overall quality of life 285.7 (SD 28.0) v. 316.7 (SD 29.8). In order to put perspective on these results, possible maximum and minimum values are also presented in Table 3. In the present study, perceived physical activity levels (activities actually performed on a regular basis such as cleaning the home, washing the laundry etc., IADL-does), which were significantly higher for subjects living in their own homes compared with those in sheltered accommodation (see pp. 168-169) and were related to the objective measures of physical activity (Table 4), may reflect the relative independence of subjects living in their own homes. Perhaps it is not surprising that single (widowed) subjects claimed that they actually did more of the IADL (IADL-does) than married subjects. Although the wives of the married subjects apparently performed the domestic chores such as washing the laundry and cleaning the house (results not shown), this was not reflected by any significant differences in the objective measures of energy expenditure due to physical activity between the groups of married and single subjects (see p. 165). It seems reasonable to speculate that other forms of physical activity may compensate for the reduced level of energy expended on IADL-does in the married subjects. For example, these particular subjects may be able to participate to a greater extent in leisure-time activities or hobbies. Alternatively, single subjects may require greater amounts of sleep that may be gained at times when married subjects are still moderately active. Despite going beyond the scope of other instruments in terms of isolating social interactions from personal pursuits, the quality-of-life instrument (MAI) used in the present study may not be sufficiently sensitive to address these points and, also because of the apparent lack of association between quality of life and energy expenditure, it is suggested that an instrument specific to physical activity patterns (e.g. heart-rate monitor, activity diaries, etc.) be applied to such studies in the future. 
The authors are indebted to Research Into Ageing for their generous support of this project, and to the subjects for their dedicated participation in the study.

\section{REFERENCES}

Benedict, F. G. (1935). Old age and basal metabolism. New England Journal of Medicine 212, 1111-1122.

Bland, J. M. \& Altman, D. G. (1986). Statistical methods of assessing agreement between two methods of clinical measurement. Lancet i, 307-310.

Brody, S. (1945). Bioenergetics of Growth. New York: Reinhold.

Bureau of the Census (1993). Current Population Reports. Special Studies. Sixty Five Plus in America. Washington, DC: Government Printing Office.

Committee on Medical Aspects of Food Policy (1991). Reference Values for Food Energy and Nutrients for the United Kingdom. Reports on Health and Social Subjects no. 41. London: H.M. Stationery Office.

Committee on Medical Aspects of Food Policy (1992). The Nutrition of Elderly People. Report on Health and Social Subjects no. 43. London: H.M. Stationery Office.

Coward, W. A. (1988). The doubly-labelled water $\left({ }^{2} \mathrm{H}_{2}{ }^{18} \mathrm{O}\right)$ method: principles and practice. Proceedings of the Nutrition Society 47, 209-218.

Department of Health and Social Security (1979). Nutrition and Health in Old Age. Report on Health and Social Subjects no. 16. London: H.M. Stationery Office.

Dubois, D. \& Dubois, E. F. (1916). A formula to estimate the approximate surface area if height and weight be known. Archives of Internal Medicine 17, 863-871.

Elia, M. (1991). Energy equivalents of $\mathrm{CO}_{2}$ and their importance in assessing energy expenditure when using tracer techniques. American Journal of Physiology 260, E75-E88.

Elia, M. (1992). Energy expenditure in the whole body. In Energy Metabolism: Tissue Determinants and Cellular Corollaries, pp. 19-59 [J. M. Kinney and H. N. Tucker, editors]. New York: Raven Press Ltd.

Elia, M. \& Livesey, G. (1992). Energy expenditure and fuel selection in biological systems: the theory and practice of calculations based on indirect calorimetry and tracer methods. In Metabolic Control of Eating, Energy Expenditure and the Bioenergetics of Obesity. World Reviews of Nutrition and Diet, vol. 70, pp. 68-131 [A. P. Simopoulos, editor]. Basel: Karger.

Food and Agriculture Organization/World Health Organization/United Nations University (1985). Energy and Protein Requirements. World Health Organization Technical Report Series no. 724. Geneva: WHO.

Fredrix, E. W. H. M., Soeters, P. B., Deerenberg, I. M., Kester, A. D. M., von Meyenfeldt, M. F. \& Saris, W. H. M. (1990). Resting and sleeping energy expenditure in the elderly. European Journal of Clinical Nutrition 44, 741-747.

Goran, M. I. \& Poehlman, E. T. (1992). Total energy expenditure and energy requirements in healthy elderly persons. Metabolism 41, 744-753.

Harris, J. A. \& Benedict, F. G. (1919). A Biometric Study of Basal Metabolism in Man. Publication no. 279. Washington, DC: Carnegie Institute of Washington.

Kleiber, M. (1975). The Fire of Life: An Introduction to Animal Energetics. Huntingdon, New York: R. E. Krieger Publishing Co.

Lawton, M. P., Moss, M., Fulcomer, M. \& Kleban, M. H. (1982). A research and service oriented multilevel assessment instrument. Journal of Gerontology 37, 91-99.

McDowell, I. \& Newell, C. (1987). Measuring Health: a Guide to Rating Scales and Questionnaires. New York and Oxford: Oxford University Press.

Mifflin, M. D., St Jeor, S. T., Hill, L. A., Scott, B. J., Daugherty, S. A. \& Koh, Y. O. (1990). A new predictive equation for resting energy expenditure in healthy individuals. American Journal of Clinical Nutrition 51, 241-247.

National Research Council (1989). Recommended Dietary Allowances, 10th ed. Washington, DC: National Academy Press.

Office of Population Censuses and Surveys (1991). General Household Survey 1989. London: H.M. Stationery Office.

Owen, O. E., Holup, J. L., D’Alessio, D. A., Craig, B. S., Polansky, M., Smalley, K. J., Kavle, E. C., Bushman, M. C., Owen, L. R., Mozzoli, M. A., Kendrick, Z. V. \& Boden, G. H. (1987). A reappraisal of the caloric requirements of men. American Journal of Clinical Nutrition 46, 875-885.

Pannemans, D. L. E. \& Westerterp, K. R. (1994). Energy and protein metabolism in the elderly. Pannemans, D.L.E. PhD Thesis, University of Limburg.

Pullicino, E., Coward, W. A. \& Elia, M. (1993). Total energy expenditure in intravenously fed patients measured by the doubly-labelled water technique. Metabolism 42, 58-64.

Quenouille, M. H., Boyne, A. W., Fisher, W. B. \& Leitch, U. (1951). Statistical Studies of Recorded Energy Expenditure of Man. Part 1. Basal Metabolism Related to Sex, Stature, Age, Climate and Race. Commonwealth Bureau of Animal Nutrition Technical Communication no. 17. Farnham Royal, Bucks.: Commonwealth Agricultural Bureaux. 
Reilly, J. J., Lord, A., Bunker, V. W., Prentice, A. M., Coward, W. A., Thomas, A. J. \& Briggs, R. S. (1993). Energy balance in healthy elderly women. British Journal of Nutrition 69, 21-27.

Roberts, S. B., Young, V. R., Fuss, P., Heyman, M. B., Fiatarone, M., Dallal, G. E., Cortiella, J. \& Evans, W. J. (1992). What are the dietary needs of elderly adults? International Journal of Obesity 16, 969-976.

Roza, A. M. \& Shizgal, H. M. (1984). The Harris Benedict equation reevaluated: resting energy requirements and the body cell mass. American Journal of Clinical Nutrition 40, 168-182.

Schofield, W. N. (1985). Predicting basal metabolic rate, new standards and review of previous work. Human Nutrition: Clinical Nutrition 39C, Suppl. 1, 5-41.

Siri, W. E. (1961). Body composition from fluid spaces and density: analysis of methods. In Techniques for Measuring Body Composition, pp. 223-244 [J. Brozek and A. Henschel, editors]. Washington, DC: National Academy Sciences, National Research Council.

Young, V. R. (1992). Energy requirements in the elderly. Nutrition Reviews 50, 95-101. 